\title{
PROSEDUR PEMERIKSAAN MSCT ANGIOGRAFI KEPALA DENGAN KLINIS STROKE
}

\author{
Karina Widya Armelia ${ }^{1)}$, Jeffri Ardiyanto ${ }^{2)}$, Andrey Nino Kurniawan ${ }^{3)}$ \\ 1) Students of Diploma-IV Radiology Technique in JTRR Health Polytechnic of Semarang \\ ${ }^{2,3)}$ Lecture of Radiodiagnostic and Radiotherapy Technique in Health Polytechnic of Semarang \\ e-mail : karinawidyaarmelia@gmail.com
}

\begin{abstract}
Background : Reconstruction used to showing the patology of stroke is MPR (Multi Planar Reconstruction). Procedure reformat and filming of MSCT Angiography examination with the clinical of stroke in Radiology Hospital Dr. Moewardi just used 3D MIP, but there was dissatisfaction with the radiologist, so the radiologist do additional reformat independently. The purpose of this study was to explain the procedure of head angiography with MSCT examination in case of stroke to know the reason for head Angiography scanning and to know the reason for using reformat and filming just in 3D MIP.

Methods : The type of research used a qualitative researchwith case study appoarch. The data were collected from March to April at Radiologi Hospital Dr. Moewardi by observation, interview with radiology technologist, radiologost and referring physician, and also documentation. Data were analyzed by using interactive model.

Results : The result of the research shows that the procedure of Head Angiography examination with MSCT in stroke cases is done by the area from mandibula to vertex. Injection contrast media $370 \mathrm{mg} / \mathrm{mL}$ in intra vena with $90 \mathrm{~mL}$ and ringer laktat 30 $\mathrm{mL}$. The examination began with scanning of the scanogram, pre contrast, and post contrast. Reformat and filming just in 3D MIP with AP projection, lateral, right oblique and left oblique several in positive and negative.

Conclusion : The reason reformat and filming just in 3D MIP because it has revealed vascularization from various angles to be evaluated and the results obtained look like a picture of Digital Substraction Angiography (DSA), making it easier for the referring physician to carry out further examination of coiling with the DSA method.
\end{abstract}

Keywords : MSCT Angiography, Stroke, 3D MIP

\section{PENDAhuluan}

Stroke adalah suatu sindrom yang ditandai dengan gejala dan atau tanda klinis yang berkembang dengan cepat yang berupa gangguan fungsional otak fokal maupun global yang berlangsung lebih dari 24 jam (kecuali ada intervensi bedah atau membawa kematian), yang tidak disebabkan oleh penyebab lain yang lebih jelas selain vaskuler(Mansjoer, 2000). Stroke ditandai dengan berkembanganya defisit neurologis presisten fokus sekunder terhadap peristiwa pembuluh darah(Gonzalez, 2006).

Pemeriksaan CT Angiografi (CTA) digunakan sebagai studi tambahan yang dijadikan pemeriksaan rutin untuk mendiagnosis carotid stenosis, intracranial atherosclerosis, dan pelebaran pembuluh darah. Bagian penting dari pemeriksaan CT Angiografi pada pasien stroke untuk meningkatkan kepastian diagnostik dan pemilihan pengobatan lanjutan pada stroke akut, salah satunya yakni dengan Intravenous tissue Plasminogen Activator (IV tPA) pada pasien dengan stroke akut (Douglas, Shamy, \& Bhattacharya, 2015).

Meskipun dalam pemeriksaan CT Angiografi terpapar radiasi, namun CTA memiliki beberapa keunggulan dibandingkan dengan MR Angiografi untuk pencitraan neurovascular salah satunya yakni waktu scanning yang lebih cepat sehingga pasien merasa lebih nyaman, tidak bergantung pada aliran pembuluh darah, dan dapat dilakukan pada pasien yang memiliki kontraindikasi untuk MR Angiografi seperti pacemakers, intravenous pumps, ventilators, dan bahan logam lainnya yang terpasang di tubuh pasien. Keunggulan lainnya yakni CTA aman terhadap artefak yang ditimbulkan oleh pergerakan dibandingkan dengan MRI, sehingga CTA harus menjadi pilihan pertama untuk pencitraan neurovascular dalam stroke(Menon \& Demchuk, 2011).

Selain teknik pemeriksaan, post processing juga menentukan tingkat keberhasilan pemeriksaan CT Angiografi dalam menampakkan patologi yang di inginkan, salah satunya dengan rekonstruksi gambar dari data awal yang di dapatkan. Rekonstruksi gambar yang dapat dilakukan pada pemeriksaan CT Angiografi kepala adalah Multi Planar Reconstruction (MPR), Maximum Intensity Projection (MIP), Volume Rendering Technique (VRT), dan Shaded Surface Display (SSD) (Addis et al., 2001).

Pemeriksaan MSCT angiografi kepala dengan klinis stroke di Instalasi Radiologi RSUD Dr. Moewardi dilakukan dengan persiapan khusus dan menggunakan media kontras untuk menampakkan 
vaskularisasi kepala. Selain media kontras, post processing juga menjadi penentu dalam menghasilkan gambar untuk menampakkan patologi yang ada. Salah satu reformat yang digunakan pada klinis stroke yakni MPR dengan potongan crossectional untuk menampakkan vaskularisasi intracranial(Paller \& Mancini, 2011), sedangkan di Instalasi Radiologi RSUD Dr. Moewardi, post processing hanya dilakukan dengan reformat 3D MIP, namun terkadang terjadi ketidakpuasan pada dokter radiolog sehingga dokter radiolog melakukan reformat tambahan secara mandiri untuk memperjelas penyebab dari stroke tersebut.

\section{Metode}

Jenis penelitian ini adalah penelitian kualitatif dengan pendekatan studi kasus. Objek penelitian meliputi 2 pasien dengan permintaan MSCT Angiografi Kepala pada klinis stroke di Instalasi Radiologi RSUD Dr. Moewardi. Subyek penelitian sebagai responden meliputi 3 radiografer, 1 dokter spesialisis radiologi, dan dokter pengirim. Penelitian ini dilakukan pada bulan Maret-April 2019. Metode pangambilan data dengan cara observasi, wawancara, dan dokumentasi. Data dianalisis menggunakan interaktif model.

\section{hasil Dan Pembahasan}

Penelitian ini menggunakan dua pasien MSCT Angiografi Kepala dengan klinis stroke. Kedua pasien tersebut melakukan persiapan sebelum pemeriksaan yaitu cek laboratorium ureum kreatinin dan $\mathrm{HbsAg}$, puasa makan minimal 6 jam sebelum pemeriksaan, keluarga pasien menandatangani surat persetujuan dilakukannya tindakan dengan menggunakan media kontras.

Penelitian ini menggunakan pesawat MSCT Toshiba Aquilion 64 Slice dengan media kontras $370 \mathrm{mg} / \mathrm{mL}$ sebanyak $90 \mathrm{~mL}$ dan larutan ringer laktat sebanyak $30 \mathrm{~mL}$ menggunakan injektor otomatis. Pasien supine diatas meja pemerikssaan dengan posisi head first. Kepala pasien diberikan fiksasi menggunakan headstrap. Tahap-tahap teknik pemeriksaan MSCT Angiografi kepala pada klinis stroke di Instalasi Radiologi RSUD Dr. Moewardi yaitu memilih protokol pemeriksaan brain DSA. Diawali dengan scanning scanogram AP dan lateral, area dari vertex hingga mandibula. Dilanjutkan dengan scanning non kontras dan scanning post kontras dengan mengambil vase arteri. Proses monitoring dilakukan dengan manual pada aorta descenden atau arteri carotis dengan delay scanning 9-13 second.
Kemudian didapatkan file volume dari hasil scanning yang berupa image data dan dilanjutkan post processing yakni dengan melakukan reformat file volume tersebut untuk di substraksi yang diambil dari hasil scanning pre kontras dan post kontras yang memiliki slice thickness, slice interval, serta gambaran yang sama, kemudian digabungkan untuk dihilangkan gambaran tulangnya serta dihasilkan gambaran 3D vaskuler yang akan ditampilkan dalam format MIP untuk mencari penyebab terjadinya stroke. Reformat dan filming 3D MIP dibuat dalam proyeksi AP, Lateral, Oblik kanan, Oblik kiri yang masing-masing dalam keadaan positif dan negatif.

\section{Persiapan Pasien}

Pemeriksaan MSCT Angiografi kepala di Instalasi Radiologi RSUD Dr. Moewardi menggunakan persiapan khusus yakni melakukan puasa makan minimal 6 jam sebelum pemeriksaan yang bertujuan untuk menghindari terjadinya aspirasi. Sebelum pemeriksaan dilakukan, pasien sudah melakukan tes laboratorium ureum, kreatinin, dan HbsAg untuk mengetahui fungsi ginjal. Kemudian pasien dan keluarga pasien diberi penjelasan terkait dengan pemeriksaan yang akan dilakukan dan dialnjutkan dengan penandatanganan surat persetujuan melakukan tindakan. Persiapan pemeriksaan MSCT Angiografi kepala dimulai dengan cek fungsi ginjal, kemudian keluarga diberi penjelasan mengenai pemeriksaan yang akan dilakukan serta diminta untuk menandatangani lembar persetujuan melakukan tindakan(Bruening \& Flohr, 2006). Menurut penulis, persiapan pasien yang dilakukan di RSUD Dr. Moewardi telah sesuai dengan teori yakni puasa sebelum pemeriksaan, cek fungsi ginjal, dan penandatanganan lembar persetujuan melakukan tindakan.

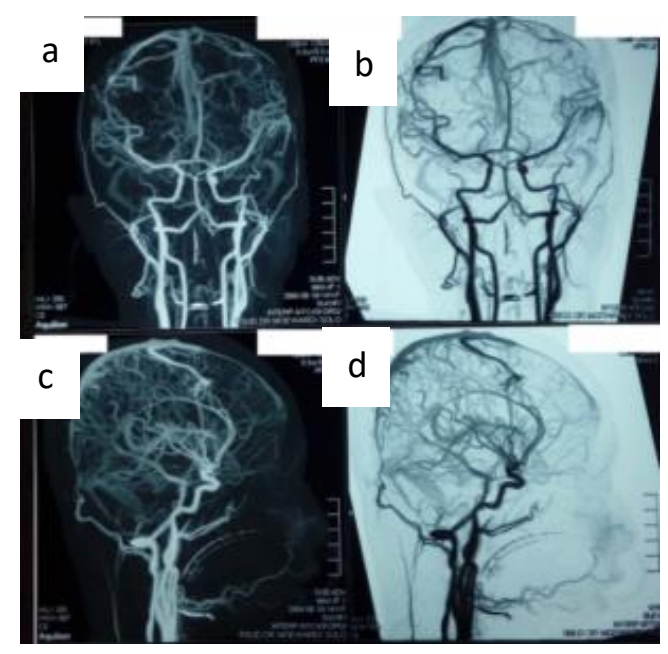


Gambar 1. Citra 3D MIP (a) Proyeksi AP kondisi positif (b) Proyeksi AP kondisi negatif (c) Proyeksi lateral kondisi positif (d) Proyeksi lateral kondisi negatif

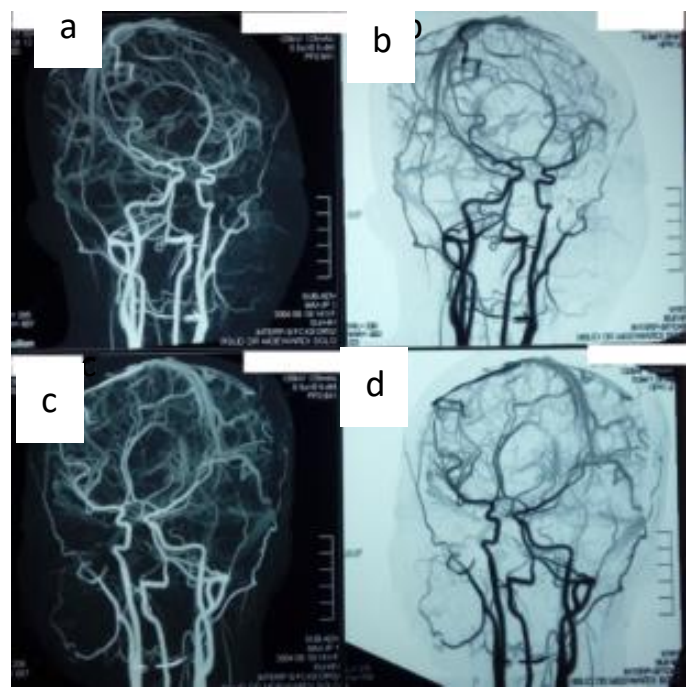

Gambar 2

Gambar 2. Citra 3D MIP (a) Proyeksi oblik kiri kondisi positif (b) Proyeksi oblik kiri kondisi negatif (c) Proyeksi oblik kanan kondisi positif (d) Proyeksi oblik kanan kondisi negatif

\section{Persiapan Alat dan Bahan}

Persiapan alat dan bahan pada pemeriksaan MSCT Angiografi Kepala di Instalasi Radiologi RSUD Dr. Moewardi meliputi : pesawat MSCT 64 Slice, alat fiksasi kepala, injektor otomatis 2 syringe, abocath ukuran 18, media kontras 370 $\mathrm{mg} / \mathrm{mL}$, dan larutan ringer laktat. Alat dan bahan yang digunakan dalam pemeriksaan MSCT Angiografi yaitu : peswat MSCT 64 Slice, alat fiksasi kepala, tabung $\mathrm{O} 2$, media kontras dan $\mathrm{NaCl}$, abocath ukuran 18/20, injektor dan tubing connector, kapas alkohol, obat anti histamine(Bruening \& Flohr, 2006). Menurut penulis, persiapan alat dan bahan yang dilakukan pada pemeriksaan MSCT Angiografi kepala dengan klinis stroke telah sesuai dengan teori.

\section{Persiapan Media Kontras}

Pemberian media kontras pada pemeriksaan MSCT Angiogarfi kepala dengan klinis stroke di Instalasi Radiologi RSUD Dr. Moewardi dilakukan secara intravena. Media kontras yang digunakan dengan konsentrasi $370 \mathrm{mg} / \mathrm{mL}$ sebanyak $90 \mathrm{~mL}$ dan larutan ringer laktat sebanyak $30 \mathrm{~mL}$ yang keduanya menggunakan flowrate $4,5 \mathrm{~mL} / \mathrm{s}$. Media kontras yang digunakan untuk pemeriksaan MSCT Angiografi memiliki konsentrasi $350 \mathrm{mg} / \mathrm{mL}$ dengan flowrate minimal $4 \mathrm{~mL} / \mathrm{s}$ (Bello et al., 2015). Sedangkan volume media kontras yang digunakan ialah $120 \mathrm{~mL}$ dengan konsentrasi 300 $\mathrm{mg} / \mathrm{mL}$ dan saline $30 \mathrm{~mL}$ (Bruening \& Flohr, 2006). Menurut penulis, penggunaan media kontras di
Instalasi Radiologi RSUD Dr. Moewardi telah sesuai dengan teori (Bello et al., 2015) untuk penggunaan flowrate, yakni menggunakan flowrate $4,5 \mathrm{~mL} / \mathrm{s}$. Volume saline yang digunakan telah sesuai dengan teori (Bruening \& Flohr, 2006) yakni sebanyak $30 \mathrm{~mL}$. Sedangkan volume media kontras yang digunakan seharusnya disesuaikan dengan berat badan pasien dan dengan pengambilan scanning yang tepat, sehingga didapatkan gambaran vaskuler yang enhance dan dapat dipastikan pasien benar-benar dalam kondisi aman karena penggunaan dosis yang sesuai.

\section{Posisi Pasien dan Teknik Scanning}

Posisi pasien pada pemeriksaan MSCT Angiografi kepala di Instalasi Radiologi RSUD Dr. Moewardi yakni supine dengan posisi head first dan telah terpasang infus pada vena cubiti kanan dengan abocath ukuran 18. MSP tubuh dan MAE diatur tepat pada lampu indikator longitudinal dan horizontal, sedangkan lampu indikator vertikal sejajar dengan OML. Batas bawah penyinaran diatur setinggi cervical 3 atau dibawah mandibula. Pada pemeriksaan MSCT Angiografi kepala, pasien diposisikan supine diatas meja pemeriksaan dengan posisi kepala dekat dengan gantry dan terpasang IV line ukuran $18 / 20$ dan scanning dimulai dari cervical 2 hingga vertex (Bruening \& Flohr, 2006). Menurut penulis, posisi pasien pada pemeriksaan MSCT Angiografi kepala di Instalasi Radiologi RSUD Dr. Moewardi telah sesuai dengan teori (Bruening \& Flohr, 2006), sedangkan area scanning dimulai dari cervical 3 tidak sesuai dengan teori karena selain bertujuan untuk penempatan trigerring, juga untuk memastikan ada atau tidaknya stenosis di daerah arteri carotis.

\section{Reformat 3D MIP}

Reformat 3D MIP dibuat dengan teknik substraksi yakni menumpuk gambar pre dan post kontras untuk menghilangkan gambaran tulang dan menghasilkan gambaran vaskuler pada rekonstruksi. Untuk menghasilkan gambar 3D MIP, slice thickness dan slice interval diatur dengan nilai $0,5 \mathrm{~mm}$ dengan jumlah gambar kurang dari 500. Dikarenakan kompleksitas pembuluh darah untuk memvisualisasikan semua cabang dan semakin tipis slice thickness yang dibuat, maka gambar yang dihasilkan semakin detail dan halus (Horton, Fishman, Km, Smith, \& Ek, 2007). Sedangkan jumlah gambar kurang dari 500 dikarenakan modalitas yang digunakan hanya mampu membaca gambar dengan kapasitas maksimal 500. Gambaran 3D MIP vaskuler yang dihasilkan akan diproyeksikan AP, lateral salah satu sisi, oblik kanan, serta oblik kiri. 


\section{Filming}

Langkah terakhir dalam rekonstruksi citra yaitu proses filming. Teknik filming MSCT Angiografi Kepala dengan klinis stroke di Instalasi Radiologi RSUD Dr. Moewardi terdiri dari 2 lembar film dimana masing-masing film berisi 4 gambar yang terdiri dari 2 proyeksi dalam kondisi positif dan negatif. Hal ini bertujuan agar masingmasing proyeksi yang dihasilkan tidak dalam ukuran terlalu kecil dan dapat dikonfirmasi gambaran vaskulernya dari kondisi positif dan negatif.

Alasan hanya melakukan reformat dan filming 3D MIP

Pemeriksaan MSCT Angiografi kepala di Instalasi Radiologi RSUD Dr. Moewardi hanya dilakukan reformat dan filming dalam 3D MIP dengan alasan, pada kasus stroke yang harus di evaluasi yakni kelainan pembuluh darah yang menjadi penyebab terjadinya stroke tersebut. filming dan reformat 3D MIP dapat menampakkan pohon-pohon pembuluh darah dari berbagai sudut pandang dengan jelas. Jika terdapat kelainan yang tampak, dapat dilakukan pengukuran langsung melalui gambaran 3D tersebut, namun hasil yang didapatkan akan lebih akurat jika dilakukan pengukuran melalui gambaran crossectional. Sedangkan di Instalasi Radiologi RSUD Dr. Moewardi hanya digunakan reformat 3D MIP yang memiliki format sama dengan DSA yang dapat menampakkan pembuluh darah dengan jelas. Karena jika terdapat kelainan, pemeriksaan lanjutan yang akan dilakukan ialah coilling dengan metode DSA.

Proses reformat pada pemeriksaan MSCT Angiografi kepala seharusnya digunakan 3D MIP dan VRT sebagai teknik pelengkap untuk oemetaan vaskuler sehingga tidak menimbulkan kesalahan interpretasi, selain itu juga dapat digunakan untuk menampakkan seberapa besra patologi yang ada karena VRT memberikan informasi tambahan selain vaskuler (Fishman et al., 2006). Karena gambaran 3D MIP tanpa gambar pelengkap dapat menimbulkan kesalahan interpretasi sehingga harus disertai gambar pelengkap yakni VRT, atau dapat juga dengan MPR dalam meningkatkan hubungan 3D.

Menurut pendapat penulis, pada pemeriksaan MSCT Angiografi kepala dengan klinis stroke sebaiknya post processing dilakukan dengan menambahkan MPR atau VRT sesuai dengan teori (Fishman et al., 2006). Untuk menegakkan diagnosis, dibutuhkan data pendukung yang lain. Seperti pada kasus pasien B dengan klinis ICH , dokter radiolog juga membutuhkan data pendukung yang berupa reformat VRT untuk mencari penyebab stroke yang ternyata dikarenakan adanya AVM, dimana AVM akan tampak lebih jelas menggunakan reformat VRT. Sedangkan di Instalasi Radiologi RSUD Dr. Moewardi hanya menggunakan refromat 3D MIP. Filming 3D MIP dibuat atas permintaan dokter pengirim yang akan mengevaluasi vaskuler yang tampak seperti gambaran DSA untuk dilakukan tindakan lanjutan berupa coilling di Cathlab dengan metode DSA bila ditemukan kelainan.

\section{Simpulan}

Prosedur pemeriksaan MSCT Angiografi Kepala dengan klinis stroke di Instalasi Radiologi RSUD Dr. Moewardi dilakukan dengan persiapan puasa makan minimal 6 jam sebelum pemeriksaan serta melakukan tes ureum kreatinin dan HbsAg. Teknik scanning dengan 3 tahap yakni scanogram, scanning pre kontras, dan scanning post kontras dengan mengambil vase arteri. Media kontras yang digunakan dengan konsentrasi $370 \mathrm{mg} / \mathrm{mL}$ sebanyak $90 \mathrm{~mL}$ dan digunakan larutan ringer laktat sebanyak $30 \mathrm{~mL}$ yang di injeksikan dengan cara intravena melalui vena cubiti kanan. Rekonstruksi dan filming hanya dalam reformat 3D MIP dalam proyeksi Ap, lateral, oblik kanan, dan oblik kiri yang masing-masing dalam kondisi positif dan negatif. 3D MIP digunakan karena mampu menampakkan vaskularisasi dari berbagai sudut untuk dilakukan evaluasi dn gambaran vaskuler yang tampak seperti gambaran DSA sehingga dapat memudahkan dokter pengirim untuk melakukan pemeriksaan lanjutan berupa coilling dengan metode DSA apabila ditemukan kelainan pada pembuluh darah.

\section{Daftar Pustaka}

Addis, K. A., Hopper, K. D., Iyriboz, T. A., Wise, S. W., Kasales, C. J., Blebea, J. S., \& Mauger, D. T. (2001). CT Angiography: In Vitro Comparison of Five Reconstruction Methods. American Journal of Roentgenology,177,1171-1176. https://doi.org/10.2214/ajr.177.5.1771171

Bello, J. A., Blackham, C. K. A., Phillips, C. D., Hetts, S. W., Srinivasan, A., Mirsky, D. M., ... Robertson, R. L. (2015). Acr-Asnr-Spr Practice Parameter for the Performance and Interpretation of Cervicocerebral Computed Tomography Angiography (Cta). American Collage of Radiology, 1076(19), 1-14. https://doi.org/https://www.acr.org//media/ACR/Files/Practice-

Parameters/CervicoCerebralCTA.pdf

Bruening, R., \& Flohr, T. (2006). Protocols For 
Multislice CT, 2nd EditionProtocols for Multislice CT 4- and 16-row Applications. Berlin: Springer.

Douglas, V., Shamy, M., \& Bhattacharya, P. (2015). Should CT Angiography be a Routine Component of Acute Stroke Imaging? The Neurohospitalis,5(3),97-100. https://doi.org/10.1177/1941874415588393

Fishman, E. K., Ney, D. R., Heath, D. G., Corl, F. M., Horton, K. M., \& Johnson, P. T. (2006). Volume Rendering versus Maximum Intensity Projection in CT Angiography: What Works Best, When, and Why. RadioGraphics, 26(3), 905-922. https://doi.org/10.1148/rg.263055186

Gonzalez, R. G. (2006). Imaging-Guided Acute Ischemic Stroke Therapy: From "Time Is Brain" to "Physiology Is Brain." American Journal of Neuroradiology,27(4),728-735. https://doi.org/https://ajnr.org/content/27/4/278

Horton, K. M., Fishman, E. K., Km, H., Smith, C., \& Ek, F. (2007). MDCT and 3D CT Angiography of Splanchnic Artery Aneurysms. AJR. American Journal of Roentgenology, 189, 641-647. https://doi.org/10.2214/AJR.07.2210

Mansjoer, A. (2000). Kapita Selekta Kedokteran jilid I. Jakarta: Media Aesculapius.

Menon, B. K., \& Demchuk, A. M. (2011). Computed Tomography Angiography in the Assessment of Patients With Stroke / TIA. The Neurohospitalis,1(4),187-199. https://doi.org/10.1177/1941874411418523

Paller, A., \& Mancini, A. (2011). Hurwitz Clinical Pediatric Dermatology: A Textbook of Skin Disorders of Childhood and Adolescence (Vol. 91). Canada: Elsevier. 